\section{Space shuttles}

\section{Peter Kemp}

Contact: A Novel. By Carl Sagan. Simon \& Schuster: 1985. Pp.432.\$18.95.

AMONG the numerous - and often numinous - quotations strewn around Carl Sagan's latest novel, is Einstein's claim that "the cosmic religious feeling is the strongest and noblest motive for scientific research". True to this belief, Sagan's saga of galactic exploration keeps juxtaposing the scriptural and the scientific: apocalyptic sects and astronomers, angels and astronauts, messiahs and supernovae, tales of mystic experience and talk of transcendental numbers. Even in shapeopening with genesis and ending with revelation - his book seems to have its eye on the Bible.

The first page records the birth of Ellie, a baby who comes into the world with a look of "puzzlement". As she grows up, this matures into intellectual curiosity especially about possible extraterrestrial life. Finding her vocation as a radioastronomer, Ellie pioneers new techniques for scanning the heavens - and, as the that there are powerful beings out there proves justified. From the vicinity of Vega, a coded communique is picked up, transmitting instructions for the manufacture of a massive machine. Despite objections from some quarters that this is a goes ahead. At last - on 31 December, 1999 - Ellie and four international colleagues board what has turned out to be a spaceship ready for launching.

Up to this point, Sagan's story has kept to fairly well-trodden ground, such as the way space research might foster "transnational" thinking and global unity: a notion regularly mooted in science fiction since the days of $\mathrm{H}$. G. Wells. The crucial test for space travel stories, though, is what happens when their characters zoom diving into the banal.

This is a hazard Sagan doesn't altogether steer his way around. Though he musters an imposing array of technical terminology - as his crew shuttle through space, they exchange arcane remarks about "time-like Killing vectors, nonAbelian gauge invariance, geodesic refocusing, eleven-dimensional KaluzaKlein treatments of supergravity" and the like - he also employs analogies that seem something of a let-down. The mysterious black tunnels along which his starcraft is whisked are, it is improbably suggested, like "a subway"; star systems loom up like stops along the line; the gigantic junction at the heart of it all is "Grand Central Station".

Even more surprisingly down-to-earth second millennium approaches, her hunch snare of Antichrist, construction work away from Earth. After take-off, the narrative is at maximum risk of nose- is the destination at which his travellers disembark: a kind of far-fetched Disneyland. Alighting on a simulation of a tropical beach - all palm trees and balmy breezes - they are greeted by aliens who have considerately assumed not merely human shape but that of their guests' "deepest loves". More suggestive of When You Wish Upon A Star than of what you might expect to find when you travel to one, these sentimental look-alikes are also designed, it appears, to figure as equivalents of scriptural divinities: "beings who live in the sky, beings enormously knowledgeable and powerful, beings concerned for our survival". "How . . theological

\section{A light on the past}

\section{Hendrik B.G. Casimir}

History of Physics: Readings from Physics Today. Edited by Spencer R. Weart and Melba Phillips. American Institute of Physics:1985. Pp.375. Pbk \$25.

WHEN, in 1948, the American Institute of Physics (AIP) launched Physics Today, it did not intend the journal to deal with the past. The new publication addressed itself to members of the AIP and of its several affiliated bodies, and aimed at keeping them informed about what was happening in physics, both from a scientific and from an institutional point of view. Only in 1952 did a contribution of a historical, or at least of a retrospective character appear in its columns, but from then on historical articles became a more or less regular feature. History of Physics - a somewhat grandiose title which is put into proportion by the inconspicuously printed subtitle, Readings from Physics Today is an anthology of such articles, together with a brief introduction.

The introduction gives a useful survey of the activities of the AIP in the field of history and of the development of other such work in the United States since the Second World War. In another respect, however, it is not entirely satisfactory; when the editors state that there was hard- the circumstances had become" Ellie reflects excitedly. But, for all the book's strainings towards some loftily spiritual sphere, its final message is mundane. Returned to Earth after her galactic gallivantings, Ellie clutches the insight that "For small creatures such as we the vastness is bearable only through love". A piece of enlightenment you'd hardly think it necessary to travel light-years to acquire, it's disappointingly typical of the way this story tends to drop from the nebular to the nebulous.

Peter Kemp is an Associate Lecturer in English at the Middlesex Polytechnic, All Saints, White Hart Lane, London N17 8HR, UK. ly any organized research into the subject before 1950 - that there were no books, no papers, no journals on the history of physics - they are taking a rather parochial view. On this side of the Atlantic we had E.T. Whittaker's great work History of the Theories of Aether and Electricity and the famous Ostwald's Klassiker. annotated reprints of important papers, to name but two examples. Moreover there were many biographies and autobiographies, and several journals dealing partly or entirely with the history of science, including physics

This, however, is a point of minor importance and should not deter prospective readers. What really matters is the selection of material and in this respect the editors have done an excellent job. Not surprisingly, the articles differ widely in style and in scope, which makes it difficult to characterize the book as a whole. The best I can do is to discuss a few typical examples.

Two papers, one by Goudsmit and one by Uhlenbeck, deal with the birth of the notion of the spinning electron and with the circumstances that surrounded it. Here we have the story of a seminal idea, related by the originators half a century later. In consequence not only do these essays give a vivid impression of quantum physics and spectroscopy in the 1920s, and of the little group working with Ehrenfest at Leiden University, but they also provide an intriguing insight into the later

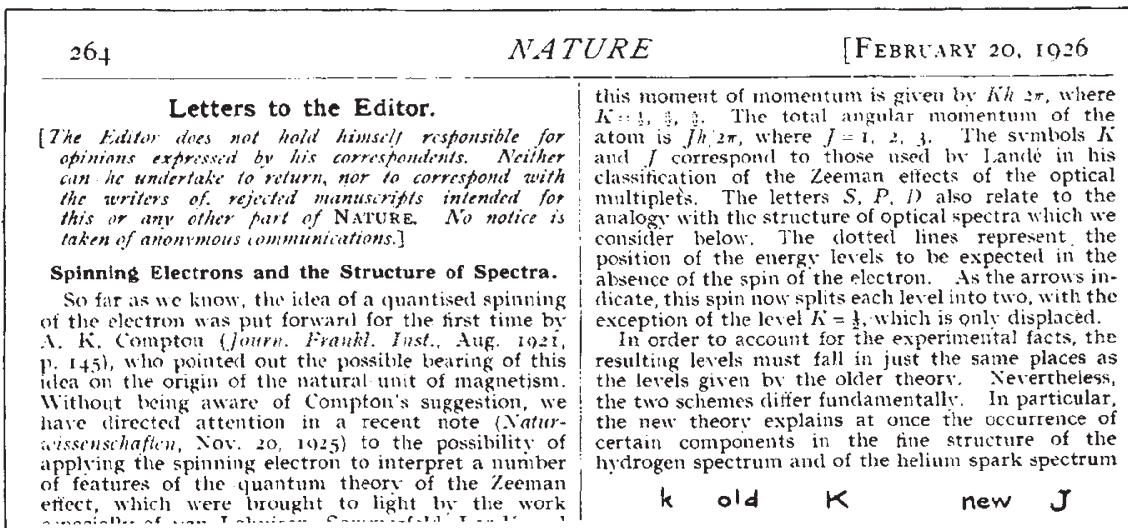

Birth of the notion of the spinning electron

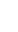


views of two senior scientists.

A delightful curiosity is the text of an address given by Einstein at Kyoto University on 14 December 1922. "How I Created the Theory of Relativity". The lecture was given in German and a Japanese physicist. J. Ishiwara, provided a translation. In 1923 Ishiwara published his Japanese text and in 1982 Physics Today printed an English translation by Yoshimasa A. Ono. Clearly, knowing that the lecture was to be translated, Einstein had formulated his ideas as concisely and simply as possible, but even so it is remarkable to see how well the text has survived two consecutive translations. There are several other articles in which the story of an important discovery or invention is told by people who were not necessarily the only originators but who did play an important part - Frisch and Wheeler on the discovery of fission is a good example, as is the history of the cyclotron told by Livingston and McMillan.

Also included are several biographical essays. Most of these are written by authors who were well-acquainted with their subjects, as their students or collaborators, which makes the stories lively and readable - here, Oliphant's "The Two Ernests" (Rutherford and Lawrence) is especially illuminating. Quite different again are the scholarly papers on specific aspects of the history of physics, for example Martin Klein's thorough study "Thermodynamics and Quanta in Planck's Work". Klein shows how Planck, a conservative rather than a revolutionary, found it hard to reconcile himself to his own innovation, but finally arrived at the conclusion "that the quantum of action played a far more significant part in phy. sics than I had originally been inclined to suspect".

It is understandable that the contributions on institutional history deal almost exclusively with American establishments, and the same is true, though to a lesser extent, of the articles grouped under the heading "Social Context". But this does not mean that they are of no interest to non-Americans, and in many cases the problems discussed are international in nature. Of particular interest here is the article by Vera Kistiakowski with the provocative title "Women in Physics: Unnecessary, Injurious and Out of Place?".

Few people will read this book from cover to cover - the editors even warn against trying to do this. But all physicists and many non-physicists will enjoy leafing through it, will admire the many excellent illustrations, and will sooner or later start reading in earnest.

$\overline{\text { Hendrik B.G. Casimir, De Zegge } 75591 \text { TT }}$ Heeze, The Netherlands, studied theoretical physics at Leiden, Copenhagen and Zürich during the 1920s and 1930s and later became joint director of research at the Philips Company, Eindhoven. His autobiography, Haphazard Reality: Half a Century of Science, was published by Harper \& Row in 1983.

\section{In the realm of the cosmocrats}

\section{Edward Harrison}

The Cosmological Distance Ladder: Distance and Time in the Universe. By Michael Rowan-Robinson. W.H. Freeman: 1985. Pp.353. \$35.95, £19.95.

COMTE de Buffon once said that the forms of life seem more like chain mail than a Great Chain of Being. Similarly the measure of the universe seems more like a network of ladders than a single cosmological distance ladder. (An irreverent person might say more like a game of snakes and ladders.)

The scale of the universe has been increased several times since Hubble wrote The Realm of the Nebulae in 1936. The Hubble term $H$ in the velocity-distance law (velocity $=H \times$ distance) has decreased in value by an order of magnitude and now stands at either 100 or $50 \mathrm{~km} \mathrm{~s}^{-1} \mathrm{Mpc}^{-1}$. The de Vaucouleurs school champions the higher value and the Sandage-Tammann school the lower value. The reciprocal of $H$ is about fifteen thousand million years and serves as a rough measure of the age of the universe.

Rowan-Robinson unifies his splendid and comprehensive survey of the universe - planets, stars, star clusters, galaxies, galaxy clusters, superclusters - with the theme of the cosmological distance ladder. In the preface he writes that, at a conference in 1976 ,
Gerard de Vaucouleurs on the one hand, and Allan Sandage and Gustav Tammann on the other, arrived at estimates of the size of the universe, as measured by the Hubble constant, differing from each other by a factor or two. Moreover, when I asked the protagonists what was the range outside which they could not imagine the Hubble constant lying, these ranges did not even overlap. ... It was to understand this disagreement that $I$ set out to write this book.

Using numerous figures, tables and appendices that display a wealth of data, the author builds an array of distance indicators and presents a difficult subject in a methodical manner. Skilfully he adjusts, deftly weighs, and adroitly averages divergent results.

The first rung on the ladder is the distance between the Sun and the Earth. Then comes the distance to the Hyades, the nearest open star cluster, determined by parallactic and moving cluster methods. The size of this preliminary and important step, now estimated to be 150 light-years, has grown 30 per cent since 1940.

We measure in Hyades-units the distance to other open clusters, applying various methods including evolutionary curve fitting. Then, with allowance for absorption of light by interstellar dust, we use Cepheids and RR Lyrae variable stars as yardsticks to gauge the distances of globular clusters in our Galaxy and of nearby galaxies in the Local Group (rival schools going different ways and making different allowances for extinction of light). Novae, supernovae and HII regions, adjusted for extinction in the observed galaxy, serve as intergalactic
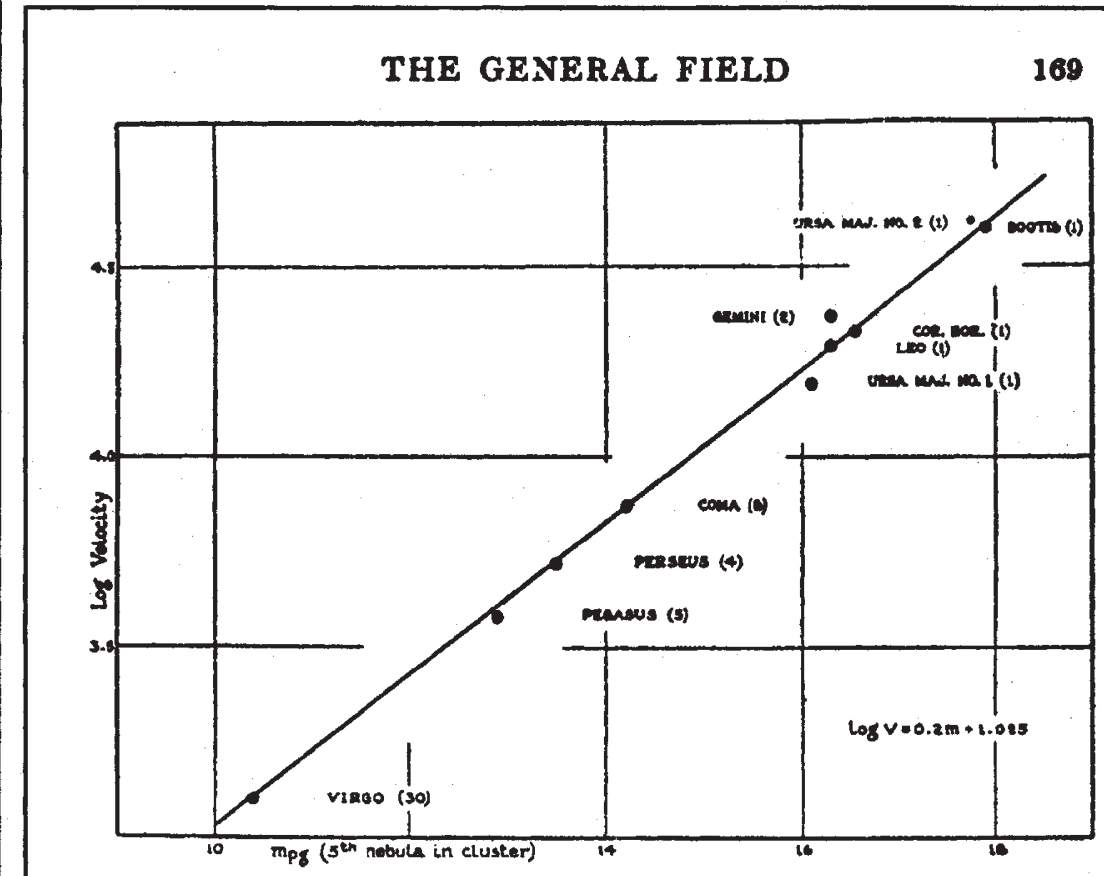

Fra. 14. Velocity-Distance Relation for Clusters.

169

(Taken from E. Hubble's The Realm of the Nebulae.) 